\title{
Health-related quality of life in a binational population with diabetes at the Texas-Mexico border
}

\author{
Nelda Mier, ${ }^{1}$ Anabel Bocanegra-Alonso, ${ }^{2}$ Dongling Zhan, ${ }^{3}$ \\ Miguel A. Zuniga, ${ }^{1}$ and Rosa I. Acosta ${ }^{2}$
}

Suggested citation N, Bocanegra-Alonso A, Zhan D, Zuniga MA, Acosta RI. Health-related quality of life in a bi-
national population with diabetes at the Texas-Mexico border. Rev Panam Salud Publica. 2008; national pop

ABSTRACT Objectives. To examine physical and mental health domains of health-related quality of life (HRQL) in a binational adult population with type 2 diabetes at the Texas-Mexico border, and to explore individual and social correlates to physical and mental health status.

Methods. Adults 18 years and older with type 2 diabetes residing in the South Texas Lower Rio Grande Valley and in Reynosa, Tamaulipas, Mexico, were recruited using a convenience sampling technique and interviewed face-to-face with a structured survey. HRQL was measured using physical and mental health summary components of the Medical Outcomes Study Short Form. HRQL correlates included demographic characteristics, health factors, access to healthcare, and family support. Samples characteristics were compared using the Student's ttest or Mann-Whitney U test. Associations between dependent and independent variables were examined using unadjusted and adjusted (multiple variable) logistic regression models. Results. There were no significant differences between Valley and Reynosa respondents in physical or mental health status scores. Valley participants with lower socioeconomic status and those perceiving their supportive relative's level of diabetes-related knowledge as "low" were more likely to report worse physical health than those lacking those characteristics. In the Reynosa group, lower physical health status was associated with duration of diabetes and insulin use. Both sample populations with clinical depressive symptoms were more likely to have worse physical and mental health than those without such symptoms.

Conclusions. HRQL is an important outcome in monitoring health status. Understanding the levels and influences of HRQL in U.S.-Mexico border residents with diabetes may help improve diabetes management programs.

Key words Quality of life; diabetes mellitus, type 2; risk factors; border health; Mexican Americans; Texas; Mexico; United States.

1 South Texas Center, School of Rural Public Health, Texas A\&M Health Science Center, McAllen, Texas, United States of America. Send correspondence and reprint requests to: Nelda Mier, South Texas Center, School of Rural Public Health, Texas A\&M Health Science Center, 2101 South McColl Rd, Room 134, McAllen, TX 78503, United States of America; telephone: (956) 668-6326; fax: (956) 6686302; email: nmier@srph.tamhsc.edu
Diabetes is a major public health issue on the U.S.-Mexico border. The

\footnotetext{
2 Unidad Académica Multidisciplinaria ReynosaAztlán, Universidad Autónoma de Tamaulipas, Reynosa, Tamaulipas, Mexico.

3 Department of Statistics, Texas A\&M University, College Station, Texas, United States of America.
}

diabetes death rate for Hispanics living in U.S. counties along the border (46.7 age-adjusted per 100,000 population) is almost three times the rate for non-Hispanic whites along the border (16.3 age-adjusted per 100,000 population) (1), while the overall prevalence 
rate among U.S.-Mexico border residents from all ethnic groups is almost twice the level of the general U.S. population $(15.7 \%$ vs. $9.6 \%$, respectively) (2-4). One study found that diabetes hospital discharge rates are higher among Hispanics living in border counties than among non-Hispanic whites along the border and Hispanics in non-border U.S. counties (5). On the Mexican side of the border, diabetes is the third leading cause of death, and the prevalence rate $(15.1 \%)$ is higher than other regions in Mexico $(4,6)$.

Diabetes is a chronic disease with high economic costs for both the U.S. and Mexico healthcare systems and communities $(6,7)$ and affects patients' health-related quality of life (HRQL). HRQL has emerged as an important outcome in monitoring the health status of a population as well as in assessing disease burden and effectiveness of health interventions (8). HRQL is related to an individual's capacity to function to the highest degree possible physically, psychologically, emotionally, and socially (9), and represents the effect of a disease subjectively on an individual (10). According to the conceptual framework developed by Wilson and Cleary (1995) (11), HRQL is influenced by biological, social, and environmental factors. Research with non-Hispanic whites shows that type 2 diabetes is associated with a reduced HRQL (2, $12,13)$. Studies also indicate that factors correlating with HRQL include diabetes-related complications $(12,14)$ and diabetes-related risk factors such as heart failure, depression, high medication intake (12), low socioeconomic status, older age, female gender, and lack of health insurance (14).

Although the U.S-Mexico border population suffers a disproportionate burden of diabetes compared to the general population in the United States and Mexico, there is a paucity of studies examining HRQL in border residents with type 2 diabetes. Healthy Border 2010, an agenda adopted by the U.S.-Mexico Border Health Commission for improving the health of border residents, identifies diabetes as one of 11 priority areas on the bilateral health agenda aiming at reducing both the diabetes mortality and hospitalization rate (15). Understanding the levels and influences of HRQL in persons with diabetes may be helpful in increasing the success of diabetes management programs. Therefore, this study aimed to: (1) examine the differences in the physical and mental domains of HRQL in a binational adult population with type 2 diabetes at the Texas-Mexico border; and (2) explore individual and social correlates to physical and mental health status for each population. Correlates of HRQL in this study included demographic characteristics, health factors, access to healthcare, and family support.

\section{MATERIALS AND METHODS}

\section{Subjects and sampling}

This was a cross-sectional study based on a survey conducted in 2004-2005 in the South Texas Lower Rio Grande Valley ("Valley") and in Reynosa, Tamaulipas, Mexico. Using a convenience sampling technique, the study recruited participants on both sides of the border from clinical settings (hospitals and physician offices). Eligibility criteria included: being 18 years of age and older; having been diagnosed with type 2 diabetes for at least one year; and willingness to give informed consent. Physicians and nurses at the recruitment sites identified patients with type 2 diabetes and referred them to the researchers. Graduate students from health-related programs on both sides of the border were trained to conduct the interviews. Participants were interviewed in either English or Spanish. On the U.S. side, the interviewers were bilingual. A total of 199 individuals in the Valley and 200 in Reynosa agreed to participate in the study. The final sample size was 399 respondents. Participants signed informed consent forms and received a box of dietetic sugar for participating in the study. This study was approved by the Texas A\&M University Institutional Review Board.

\section{Measures}

The dependent variable, HRQL, was assessed using the Medical Outcomes Study Short Form (SF-8 ${ }^{\mathrm{TM}}$ ) instrument. The SF- $8^{\mathrm{TM}}$ health survey is an 8 -item survey that provides a health profile consisting of two summary components: physical component summary (PCS) and mental component summary (MCS) (16). Although both summary components are continuous variables (as measured by the SF- $8^{\mathrm{TM}}$ ), a different calculation was used under two global categories. To examine variables in a logistic fashion, PCS and MCS were divided by the median, creating the categories: "PCS Lower vs. Higher score" and "MCS Lower vs. Higher score." The median was used to create these global categories because the PCS and MCS scales were not normally distributed. In studies with skewed distributions, use of the median rather than the mean has been found to be more accurate in representing the majority of cases $(17,18)$. The medians for the PCS and MCS were 42.36 and 46.65 , respectively. The median was calculated for all participants because there were no significant median differences between the two groups included in the study.

Independent variables examined in the study included demographic and health factors, access to healthcare, and family support. Demographic variables included gender, age (mean and standard deviation; various age groups), marital status ("not married" vs. "married"), education level ("less than high school" vs. "high school or more"), and socioeconomic status ("low" vs. "high"). Socioeconomic level was assessed by asking participants about their employment status, an indicator of socioeconomic position $(19,20)$. Household income was not included due to missing values.

Health factors were based on self-reported information and included: Body Mass Index (BMI); age when diagnosed with diabetes (mean and standard deviation); duration with diabetes ("less than 10 years" vs. "10 years or more"); high blood pressure ("yes" vs. "no"); heart disease ("yes" vs. "no"); high cho- 
lesterol ("yes" vs. "no"); insulin use ("yes" vs. "no"); amputations ("yes" vs. "no"); smoking ("yes" vs. "no"); and depressive symptoms ("clinical" vs. "nonclinical"). BMI was calculated from study participants' self-reported heights and weights. BMI was expressed as weight (in kilograms) divided by the square of height (in meters) and categorized according to the parameters of the Centers for Disease Control and Prevention (CDC) (21): "normal" (18.5-24.9 $\left.\mathrm{kg} / \mathrm{m}^{2}\right)$, "overweight" (25-29.9 kg/ $\left.\mathrm{m}^{2}\right)$, "obesity" (30-34.9 kg/m²), and "severe obesity" ( $35 \mathrm{~kg} / \mathrm{m}^{2}$ and higher). Depressive symptoms were measured using the English and Spanish versions of the 20-item Center for Epidemiological Studies Depression Scale (CES-D). The reliability and validity of the scale have been tested in general and clinical populations, yielding very good internal consistency, with an alpha of 0.85 for the general population and 0.90 for a psychiatric (clinical) population. Scores of 16 and above indicate clinical depressive symptoms $(22,23)$.

Access-to-healthcare variables included number of doctor visits, emergency room (ER) visits, and hospital stays, as well as diet counseling and diabetes education sessions over the past 12 months ("never" vs. "one or more times"). "Glucose level check" was measured using the question, "How many times, on average, do you check your blood sugar per week"? As a majority of Reynosa respondents did not check their glucose level daily or weekly, the following categories were created for the purpose of analysis: "never," "monthly," "weekly," and "daily."

Family support was measured using the Diabetes Family Behavior Checklist (DFBC), which assesses the actions of the relative identified by participants as the person most supportive of their efforts to manage their diabetes. DFBC items include the supportive relative's behaviors related to medication, glucose testing, exercise, diet, and "in general." A positive summary score ("high" vs. "low" family support) was obtained by averaging the frequency ratings over all five supportive behaviors. The reliability and predictive validity of this scale is between 0.64 and 0.84 . The DFBC also asks the participant to rate the diabetes-related knowledge level of the supportive relative ("low" vs. "moderate" vs. "high") (24).

\section{Statistical analyses}

Summary statistics were calculated to describe the population in terms of sociodemographic status, HRQL, and other variables. These statistics included means, standard deviations, and/or percentages, as appropriate. Study participant demographic, health, characteristics were compared using the Student's t-test or Mann-Whitney U test. Associations between dependent and independent variables were examined using unadjusted and adjusted healthcare access, and family support

(multiple variable) logistic regression models. The cross-tabulation method and Pearson chi-square test were used to analyze associations in univariate analysis to derive the percentage of each independent variable significant to PCS and MCS. Multivariate analyses were reported using odds ratios (OR), 95\% confidence intervals $(\mathrm{CI})$, and $p$ values. A $p$ value of $<0.05$ was considered significant for all statistical tests conducted. The analyses were performed using the Statistical Package for the Social Sciences (SPSS version 13.0 for Windows; SPSS Inc., Chicago, IL, USA) (25).

\section{RESULTS}

Table 1 shows the descriptive characteristics of the two samples, Valley respondents and Reynosa respon-

TABLE 1. Descriptive characteristics and differences between the two sample populations, South Texas Lower Rio Grande Valley and Reynosa, Tamaulipas, Mexico, 2004-2005

\begin{tabular}{|c|c|c|c|c|c|}
\hline \multirow[b]{2}{*}{ Variable } & \multicolumn{2}{|c|}{ Valley } & \multicolumn{2}{|c|}{ Reynosa } & \multirow[b]{2}{*}{$P$ value } \\
\hline & $(n=199)^{\mathrm{a}}$ & $(\%)^{b}$ & $(n=200)^{\mathrm{a}}$ & $(\%)^{b}$ & \\
\hline Gender & & & & & 0.004 \\
\hline Female & 126 & 63.3 & 153 & 76.5 & \\
\hline Male & 73 & 36.7 & 47 & 23.5 & \\
\hline Age $\left[\right.$ mean $\left.\left(S D^{d}\right)\right]$ & $58.89(14.05)$ & & $55.76(12.24)$ & & 0.006 \\
\hline $18-34$ & 12 & 6.0 & 3 & 1.5 & \\
\hline $35-44$ & 17 & 8.5 & 39 & 19.7 & \\
\hline $45-54$ & 48 & 24.1 & 54 & 27.3 & \\
\hline $55-64$ & 42 & 21.1 & 53 & 26.8 & \\
\hline $65+$ & 80 & 40.2 & 49 & 24.7 & \\
\hline Marital status & & & & & 0.384 \\
\hline Not married & 69 & 34.7 & 77 & 38.9 & \\
\hline Married & 130 & 65.3 & 121 & 61.1 & \\
\hline Education & & & & & 0.000 \\
\hline$<$ High school & 102 & 51.3 & 140 & 70.4 & \\
\hline$\geq$ High school & 97 & 48.7 & 59 & 29.6 & \\
\hline Socioeconomic status & & & & & 0.220 \\
\hline Low & 147 & 74.6 & 158 & 79.8 & \\
\hline High & 50 & 25.4 & 40 & 20.2 & \\
\hline Ethnicity & & & & & $N A^{e}$ \\
\hline Mexican American & 172 & 91.0 & - & - & \\
\hline Non-Hispanic white & 15 & 7.9 & - & - & \\
\hline Non-Hispanic black & 1 & 0.5 & - & - & \\
\hline Native American & 1 & 0.5 & - & - & \\
\hline Country of birth & & & & & \\
\hline Mexico & 82 & 41.2 & 200 & 100 & 0.000 \\
\hline United States & 114 & 57.3 & 0 & 0 & \\
\hline
\end{tabular}

a Due to missing data, the total number of individuals for each variable may be less than 199 for the Valley sample and less than 200 for the Reynosa sample.

b Valid percentage.

${ }^{c}$ Significant difference $(P<0.05)$ between the two groups according to the independent-samples Student's $t$-test or the twoindependent-samples Mann-Whitney U test.

d Standard deviation.

e Not applicable. 
TABLE 2. Differences in PCS, MCS, and other health indicators between the two sample populations, South Texas Lower Rio Grande Valley and Reynosa, Tamaulipas, Mexico, 2004-2005

\begin{tabular}{|c|c|c|c|c|c|}
\hline \multirow[b]{2}{*}{ Variable } & \multicolumn{2}{|c|}{ Valley } & \multicolumn{2}{|c|}{ Reynosa } & \multirow[b]{2}{*}{$P$ value $^{\mathrm{C}}$} \\
\hline & $(n=199)^{\mathrm{a}}$ & $(\%)^{b}$ & $(n=200)^{\mathrm{a}}$ & $(\%)^{b}$ & \\
\hline \multicolumn{6}{|l|}{ Health-related quality of life } \\
\hline $\mathrm{PCS}\left[\right.$ mean $\left.\left(\mathrm{SD}^{\mathrm{d}}\right)\right]$ & $41.65(11.73)$ & & $41.40(10.21)$ & & 0.826 \\
\hline MCS [mean (SD)] & $45.35(10.84)$ & & $44.75(10.11)$ & & 0.571 \\
\hline Body Mass Index & & & & & 0.002 \\
\hline Normal & 22 & 12.4 & 39 & 25.3 & 0.991 \\
\hline Overweight & 54 & 30.3 & 45 & 29.2 & \\
\hline Obesity & 43 & 24.2 & 38 & 24.7 & \\
\hline Severe obesity & 59 & 33.1 & 32 & 20.8 & \\
\hline Smoking & 15 & 7.5 & 23 & 11.5 & 0.183 \\
\hline \multicolumn{6}{|l|}{ Age when diagnosed with diabetes } \\
\hline [mean (SD)] & $48.58(15.00)$ & & $45.05(13.18)$ & & 0.013 \\
\hline Duration of diabetes (years) & & & & & 0.991 \\
\hline$<10$ & 109 & 55.6 & 110 & 55.6 & \\
\hline$\geq 10$ & 87 & 44.4 & 88 & 44.4 & \\
\hline High blood pressure (yes) & 132 & 66.3 & 120 & 60.0 & 0.190 \\
\hline Heart disease (yes) & 68 & 34.2 & 46 & 23.0 & 0.014 \\
\hline High cholesterol (yes) & 125 & 62.8 & 79 & 39.5 & 0.000 \\
\hline Insulin use (yes) & 107 & 53.8 & 40 & 20.0 & 0.000 \\
\hline Amputations (yes) & 10 & 5.0 & 8 & 4.0 & 0.630 \\
\hline Depressive symptoms & & & & & 0.376 \\
\hline Non-clinical & 127 & 63.8 & 119 & 59.5 & \\
\hline Clinical & 72 & 36.2 & 81 & 40.5 & \\
\hline
\end{tabular}

a Due to missing data, the total number of individuals for each variable may be less than 199 for the Valley group and less than 200 for the Reynosa group.

b Valid percentage.

${ }^{c}$ Significant difference $(P<0.05)$ between the two groups according to the independent-samples Student's $t$-test or the two-independentsamples Mann-Whitney U test.

d Standard deviation.

dents. Significant differences between samples were found for gender, age, and education.

Tables 2 and 3 show the differences between the samples in relation to the PCS and MCS mean, personal health, and healthcare variables. Compared to respondents in Reynosa, significantly more Valley participants visited the doctor more than once in the past 12 months and were using insulin. Reynosa respondents received statistically significantly more diet counseling sessions than Valley participants. More than half of the participants in both samples reported a high level of family support, with no significant differences between samples.

Table 4 shows the univariate (unadjusted) logistic regression analyses. Only variables that were statistically significant for PCS or MCS in either sample population, according to the Pearson chi-square test, are listed in the table. Analyzed individually, education, socioeconomic status, BMI, glu- cose level checks, years with diabetes, ER visits, hospital stays, diet counseling, depressive symptoms, and relative's level of diabetes-related knowledge (as perceived by the respondent) had a statistically significant association with PCS among Valley participants. In addition, in this group, ER visits, hospital stays, and depressive symptoms were significantly associated with MCS.

Among Reynosa participants, duration of diabetes, hypertension (high blood pressure), insulin use, glucose level checks, ER visits, and clinical depressive symptoms were statistically significant to PCS. In this group, those who had low socioeconomic status and reported clinical depressive symptoms were more likely to have lower MCS.

Table 5 presents the results from the multivariate (adjusted) logistic regression analyses. Among Valley respondents, low socioeconomic status and having a supportive relative with a low level of diabetes-related knowledge (as perceived by the study participant) were predictors of worse physical health status than those without those characteristics. In addition, respondents from this group with clinical depressive symptoms were more likely to report worse physical health as well as worse mental health than those without such symptoms. In the Reynosa group, the strongest multivariate relationships with lower PCS were duration of diabetes, insulin use, and clinical depressive symptoms. Reynosa participants with clinical depressive symptoms were more likely to be in worse physical and mental health status than those with non-clinical symptoms.

\section{DISCUSSION}

To the best of the authors' knowledge, this is the first study to assess HRQL and its correlates in a binational 
TABLE 3. Differences in healthcare factors and family support between the two sample populations, South Texas Lower Rio Grande Valley and Reynosa, Tamaulipas, Mexico, 2004-2005

\begin{tabular}{|c|c|c|c|c|c|}
\hline \multirow[b]{2}{*}{ Variable } & \multicolumn{2}{|c|}{ Valley } & \multicolumn{2}{|c|}{ Reynosa } & \multirow[b]{2}{*}{$P$ value $^{\mathrm{c}}$} \\
\hline & $(n=199)^{\mathrm{a}}$ & $(\%)^{b}$ & $(n=200)^{\mathrm{a}}$ & $(\%)^{b}$ & \\
\hline Glucose level check & & & & & 0.000 \\
\hline Never & 13 & 6.5 & 22 & 11.2 & \\
\hline Monthly & 2 & 1.0 & 137 & 69.5 & \\
\hline Weekly & 28 & 14.1 & 30 & 15.2 & \\
\hline Daily & 156 & 78.4 & 8 & 4.1 & \\
\hline ER visits in past 12 months & & & & & 0.211 \\
\hline Never & 141 & 70.9 & 130 & 65 & \\
\hline$\geq 1$ & 58 & 29.1 & 70 & 35 & \\
\hline Doctor visits in past 12 months & & & & & 0.000 \\
\hline Never & 1 & 0.5 & 56 & 28 & \\
\hline$\geq 1$ & 198 & 99.5 & 144 & 72 & \\
\hline Hospital stays in past 12 months & & & & & 0.856 \\
\hline Never & 137 & 68.8 & 136 & 68 & \\
\hline$\geq 1$ & 62 & 31.2 & 64 & 32 & \\
\hline Diet counseling in past 12 months & & & & & 0.000 \\
\hline Never & 118 & 59.3 & 78 & 39 & \\
\hline Once & 34 & 17.1 & 42 & 21 & \\
\hline$\geq 1$ & 47 & 23.6 & 80 & 40 & \\
\hline Diabetes education in past & & & & & \\
\hline $\begin{array}{l}12 \text { months } \\
\text { Never }\end{array}$ & & & & & 0.074 \\
\hline Never & 135 & 67.8 & 155 & 77.5 & \\
\hline Once & 32 & 16.1 & 16 & 8 & \\
\hline$\geq 1$ & 32 & 16.1 & 29 & 14.5 & \\
\hline Family support & & & & & \\
\hline High & 107 & 53.8 & 100 & 50 & 0.452 \\
\hline Low & 92 & 46.2 & 100 & 50 & \\
\hline $\begin{array}{l}\text { Supportive relative's diabetes- } \\
\text { related knowledge level }\end{array}$ & & & & & 0.000 \\
\hline Low & 42 & 21.6 & 92 & 46 & \\
\hline Moderate & 85 & 43.8 & 71 & 35.5 & \\
\hline High & 67 & 34.5 & 37 & 18.5 & \\
\hline
\end{tabular}

a Due to missing data, the total number of individuals for each variable may be less than 199 for the Valley group and less than 200 for the Reynosa group.

b Valid percentage.

c Significant difference $(P<0.05)$ between the two groups according to the independent-samples Student's $t$-test or the twoindependent-samples Mann-Whitney U test.

${ }^{\mathrm{d}}$ Based on study participant's perception.

border population with type 2 diabetes. HRQL levels and personal and social correlates were examined in adults with type 2 diabetes residing in the Valley and in Reynosa at the Texas-Mexico border.

There were no statistically significant differences in physical and mental health status scores between Valley and Reynosa [border] study participants. This is not surprising, considering that the U.S.-Mexico border is a melting pot of cultures and behaviors. Despite major differences between the United States and Mexico in terms of the organization of their health care systems, U.S.-Mexico border residents share many health prob- lems and are economically and culturally interdependent (15).

In terms of physical health, on a scale of 0-100 (with " 0 " representing "worst possible health" and "100" representing "best possible health), study participants on both sides of the border with diabetes reported slightly higher mean scores compared to those with diabetes in the general U.S. population (U.S. border, 41.65; Mexico border, 41.40; general U.S. population, 39.30) (26). One explanation for this discrepancy is that this study's binational sample may have included patients with less severe disease and comorbid conditions than those included in the general U.S. sample.
The results for Valley respondents indicate lower physical health status was correlated with low socioeconomic status-a finding consistent with previous studies (14, 27-29). However, this association was not found among Reynosa respondents.

Perhaps the most important finding of this study is that clinical depressive symptoms had a statistically significant association with decreased physical and mental health status in both Valley and Reynosa participants. Previous studies show that depression is a predictive factor of reduced HRQL $(10,12,28,30-34)$. In this study about $40 \%$ of participants in both samples reported clinical depressive symptoms. As opposed to the results for physical health status, based on the same scale (0-100), study statistics indicated U.S.Mexico border residents with diabetes had a slightly worse mental health status than those among the general U.S. population suffering from the disease (26) (U.S. border respondents, 45.45; Mexico border respondents, 44.75; general U.S. population, 47.90). This finding has important public health implications for the binational border agenda, underscoring the need for healthcare professionals and policymakers to pay more attention to the mental well-being of border residents with diabetes. Depression has been associated with diabetes complications (35), poor glycemic control (36), and low treatment adherence $(37,38)$. Moreover, Healthy People 2010 identifies diabetes and mental health issues as border health priorities and recognizes that access to mental health services along the U.S-Mexico border is problematic due to a shortage of specialty mental health providers and services (15). Thus, culturally sensitive interventions and services as well as comprehensive health policies are needed to address any deficits in both the U.S. and Mexican mental healthcare systems.

As shown in Table 5, insulin use correlated significantly with lower physical health status in the multivariate analyses among respondents in Reynosa. A statistically significant association was not found in the Valley 


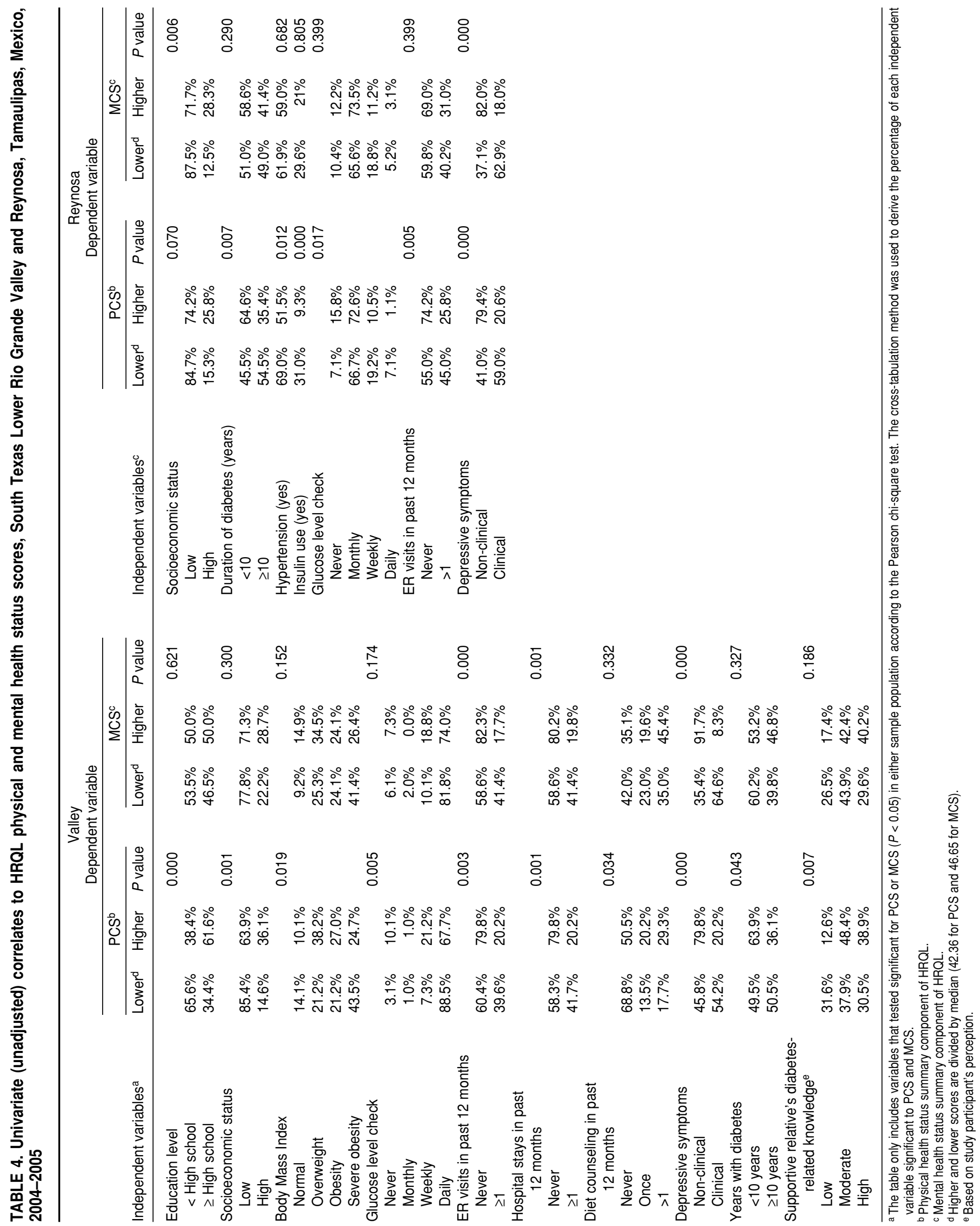




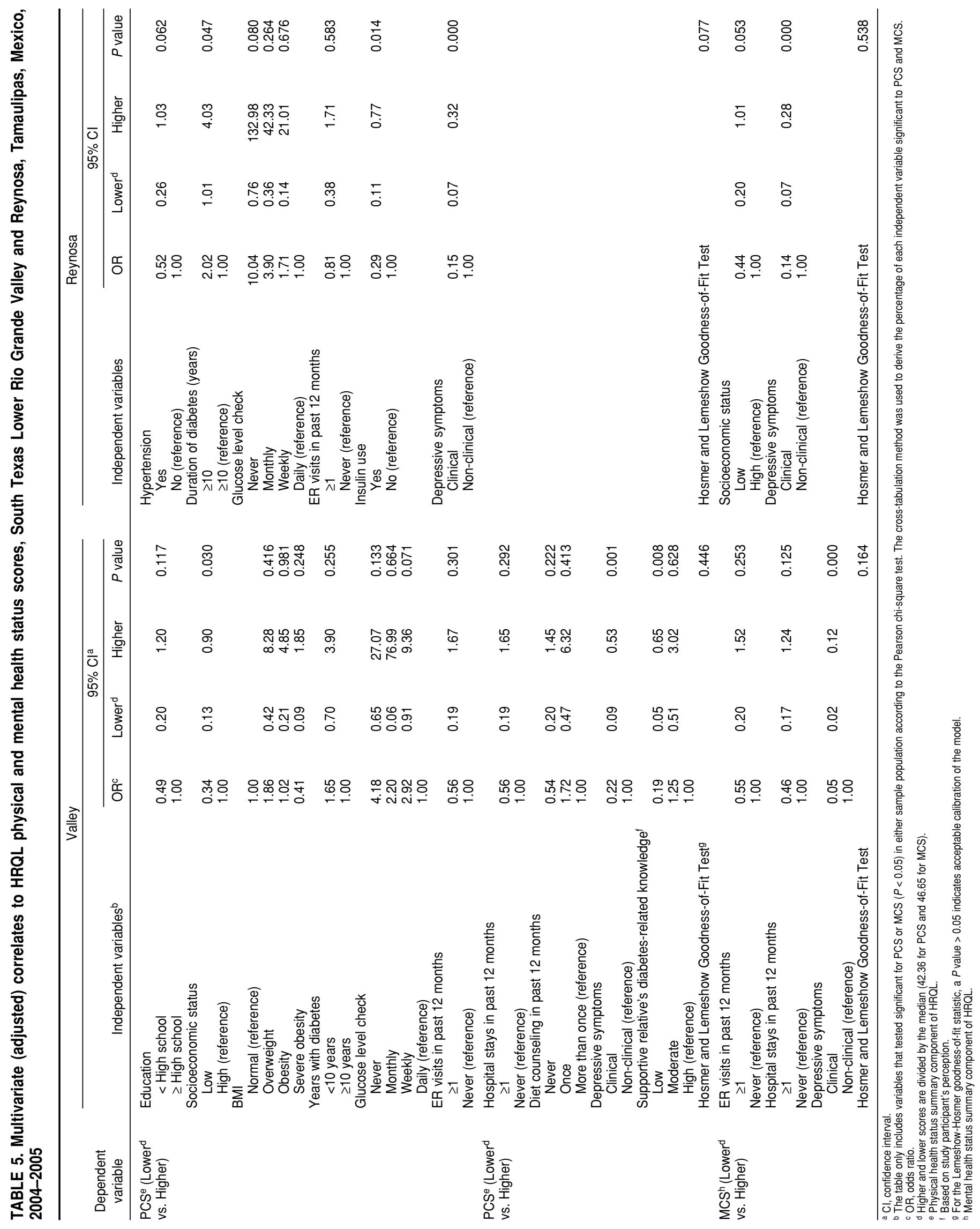


sample. This finding resonates with previous research showing that insulin use is a predictor of decreased HRQL (10, 27, 39-42). Twenty percent of Reynosa participants reported use of insulin compared to $53.8 \%$ of their counterparts in the Valley (see Table 3 ), a finding that is also consistent with previous research (42). However, it should be noted that the percentage of Reynosa insulin users in this study $(20 \%)$ was higher than that reported in Mexican national surveys with Mexican cohorts from non-border regions $(4.6 \%$ to $5.8 \%)(6,43)$. To better understand the impact of insulin use within a public health perspective, further research should focus on examining factors influencing insulin-related behaviors among border (U.S. and Mexican) patients with diabetes, including attitudes and beliefs toward insulin use, insulin-related knowledge deficits among health providers, and issues of affordability.

Another study finding was that Mexican respondents with less than 10 years with diabetes were more likely to have worse physical health status than those with long-term experience with the disease (10 years or more). Other studies have found this association $(14,39,41,44)$. Diabetes self-management education, at diagnosis, may thus be beneficial to patients.

Valley respondents perceiving that their supportive relative had poor diabetes-related knowledge were more likely to have worse physical health than those with supportive relatives with good knowledge of the dis- ease (as perceived by the study participant). Research indicates that family encouragement of healthy behaviors related to diabetes management may be a key factor in providing appropriate support to individuals with diabetes $(45,46)$. For instance, Wilson et al. (47) found that meal planning and medication reminders from relatives are critical for treatment adherence among individuals with diabetes. Health interventions on both sides of the border targeting residents of Mexican origin with diabetes should consider the inclusion of patients' relatives, as family is a very important construct in Mexican culture (48).

Although some studies found a significant correlation between obesity and HRQL $(33,39,40)$, this study did not-consistent with the results of a 2006 study by Wexler et al. (41). Further investigation is warranted to better understand the perception that border patients have toward obesogenesis and obesity-related behaviors as well as its influence on diabetes burden and complications.

This study had several limitations. First, the use of a convenience sample of patients diagnosed with type 2 diabetes limits generalizations, so causal inferences cannot be made. Furthermore, due to the heterogeneity of the samples in terms of ethnicity and use of language (English and Spanish), study findings may not be generalized to all border residents with type 2 diabetes. In addition, the use of both English and Spanish in the interviews may have introduced measurement errors. Finally, both dependent and independent variables were measured using a selfreporting instrument, which carries intrinsic respondent biases.

Despite its limitations, this may be the first binational study documenting the impact of personal and social factors on HRQL among adults with type 2 diabetes from both sides of the Texas-Mexico border. Assessing the HRQL of adults with type 2 diabetes in these populations may advance public health research and border policy efforts to increase the quality and years of healthy life of those affected by this debilitating disease.

Acknowledgments. This research was supported by the Texas Department of State Health Services and the Health Services Research Program, a collaborative research venture of the Texas A\&M Health Science Center (TAMHSC) School of Rural Public Health (SRPH), the Scott and White Hospital and Clinic College of Medicine, and the Scott and White Health Plan. The authors wish to extend their gratitude to Maria Alen of the TAMHSC; Diana Garcia and Pama Ellis of the Rio Grande Regional Hospital Diabetes Management Center; Josefa Lopez and Carolina Rivera of the Hospital General de Reynosa; Marcel Twahira and Juan Campos, local physicians; and Grace Lawson of the El Milagro Clinic for their assistance and insightful input during the design and implementation of this study.

\section{REFERENCES}

1. U.S. Centers for Disease Control and Prevention, National Center for Health Statistics. QuickStats: diabetes death rate for Hispanics compared with non-Hispanic whites-United States versus counties along the U.S.-Mexico border, 2000-2002. MMWR Morbid Mortal Wkly Rep. 2006;55(32):882.

2. Rubin RR, Peyrot M. Quality of life and diabetes. Diabetes Metab Res Rev. 1999;15(3):205-18.

3. U.S. Centers for Disease Control and Prevention, National Center for Chronic Disease Pre- vention and Health Promotion. Diabetes Public Health Resource. Data \& trends. National Diabetes Surveillance System. State-specific estimates of diagnosed diabetes among adults [Internet site]. Atlanta: U.S. Department of Health and Human Services. Available from: http://www.cdc.gov/diabetes/statistics / prev/state/tPrevalenceTotal.htm. Accessed 2 August 2006.

4. Pan American Health Organization; Centers for Disease Control and Prevention. The U.S.-
Mexico Border Diabetes Prevention and Control Project: first report of results [Internet site]. Washington: PAHO; 2005. Available from: http://www.fep.paho.org/english/ publicaciones/Diabetes/Diabetes $\% 20$ first $\%$ 20report\%20of\%20Results.pdf. Accessed 15 November 2006.

5. Albertorio-Diaz JR, Notzon FC, RodriguezLainz A. Diabetes hospitalization at the U.S.Mexico border. Prev Chronic Dis [serial online]. 2007 Apr. Available from: http://www. 
cdc.gov/pcd/issues/2007/apr/06_0073.htm. Accessed 30 April 2007.

6. Rull JA, Aguilar-Salinas CA, Rojas R, RiosTorres JM, Gomez-Perez FJ, Olaiz G. Epidemiology of type 2 diabetes in Mexico. Arch Med Res. 2005;36(3):188-96.

7. Killilea T. Long-term consequences of type 2 diabetes mellitus: economic impact on society and managed care. Am J Managed Care. 2002; 8(16 suppl):S441-9.

8. U.S. Department of Health and Human Services. Healthy People 2010. 2nd ed. Vols. I-II: Understanding and improving health and Objectives for improving health. Washington: U.S. Government Printing Office; 2000.

9. Giachello AL. Health outcomes research on Hispanics/Latinos. J Med Systems. 1996; 20(5):235-54.

10. Wändell PE. Quality of life of patients with diabetes mellitus: an overview of research in primary health care in the Nordic countries. Scand J Prim Health Care. 2005;23(2):68-74.

11. Wilson IB, Cleary PD. Linking clinical variables with health-related quality of life. A conceptual model of patient outcomes. JAMA. 1995;273(1):59-65.

12. Wexler DJ, Grant RW, Wittenberg E, Bosch JL, Cagliero E, Delahanty L, et al. Correlates of health-related quality of life in type 2 diabetes. Diabetologia. 2006;49(7):1489-97.

13. Manuel DG, Schultz SE. Health-related quality of life and health-adjusted life expectancy of people with diabetes in Ontario, Canada, 1996-1997. Diabetes Care. 2004;27(2):407-14.

14. Glasgow RE, Ruggiero L, Eakin EG, Dryfoos J, Chobanian L. Quality of life and associated characteristics in a large national sample of adults with diabetes. Diabetes Care. 1997; 20(4):562-7.

15. U.S.-Mexico Border Health Commission. Healthy Border 2010: an agenda for improving health on the United States-Mexico border. El Paso (TX): USMBHC; 2003.

16. Ware JE, Kosinski M, Dewey JE, Gandek B. How to score and interpret single-item health status measures: a manual for users of the SF$8^{\mathrm{TM}}$ Health Survey. Lincoln (RI): QualityMetric Inc.; 2001.

17. Ottenbacher KJ. The interpretation of averages in health professions research: an empirical examination. Eval Health Prof. 1993;16(3): 333-41.

18. Dreger RM. Sorting data sets and computing medians for skewed distributions. Educ Psychol Meas. 1993;55(5):785-90.

19. Powers MG. Measures of socioeconomic status: an introduction. In: Powers MG, ed. Measures of socioeconomic status: current issues. Boulder (CO): Westview; 1981. Pp. 1-28.

20. Krieger N, Williams DR, Moss NE. Measuring social class in U.S. public health research: concepts, methodologies, and guidelines. Annu Rev Pub Health. 1997;18(1):341-78.

21. U.S. Centers for Disease Control and Prevention. BMI-Body Mass Index [Internet site]. Atlanta: CDC. Available from: http://www. cdc.gov/nccdphp/dnpa/bmi/index.htm. Accessed 25 August 2005.

22. Radloff LS. The CES-D scale: a self-report depression scale for research in the general population. App Psychol Meas. 1977;1(3):385-401.

23. Hann D, Winter K, Jacobsen P. Measurement of depressive symptoms in cancer patients: evaluation of the Center for Epidemiological Studies Depression Scale (CES-D). J Psychosomatic Res. 1999;46(5):437-43.

24. Glasgow RE, Toobert DJ. Social environment and regimen adherence among type II diabetic patients. Diabetes Care. 1988;11(5):377-86.

25. SPSS Inc. Statistical Package for the Social Sciences (SPSS) for Windows, version 13.0. Chicago: SPSS Inc.; 2004.

26. Ware JE, Kosinski M, Keller SD. SF-36 ${ }^{\circledR}$ Physical and Mental Health Summary Scales: a user's manual. Boston: The Health Institute, New England Medical Center; 1994.

27. Rejeski WJ, Lang W, Neiberg RH, Van Dorsten B, Foster GD, Maciejewski ML, et al. Correlates of health-related quality of life in overweight and obese adults with type 2 diabetes. Obesity. 2006;14(5):870-83.

28. Maddigan SL, Feeny DH, Majumdar SR, Farris $\mathrm{KB}$, Johnson JA. Understanding the determinants of health for people with type 2 diabetes. Am J Public Health. 2006;96(9):1649-55.

29. Connell CM, Davis WK, Gallant MP, Sharpe PA. Impact of social support, social cognitive variables, and perceived threat on depression among adults with diabetes. Health Psychol. 1994;13(3):263-73.

30. Paschalides C, Wearden AJ, Dunkerley R, Bundy C, Davies R, Dickens CM. The associations of anxiety, depression and personal illness representations with glycaemic control and health-related quality of life in patients with type 2 diabetes mellitus. J Psychosomatic Res. 2004;57(6):557-64.

31. Hänninen JA, Takala JK, KeinänenKiukaanniemi SM. Depression in subjects with type 2 diabetes: predictive factors and relation to quality of life. Diabetes Care. 1999; 22(6):997-8.

32. Chyun DA, Melkus GD, Katten DM, Price WJ, Davey JA, Grey N, et al. The association of psychological factors, physical activity, neuropathy, and quality of life in type 2 diabetes. Biol Res Nurs. 2006;7(4):279-88.

33. Brown GC, Brown MM, Sharma S, Brown H, Gozum M, Denton P. Quality of life associated with diabetes mellitus in an adult population. J Diabetes Complications. 2000;14(1): $18-24$.

34. Kohen D, Burgess AP, Catalán J, Lant A. The role of anxiety and depression in quality of life and symptom reporting in people with diabetes mellitus. Qual Life Res. 1998;7(3): 197-204.

35. de Groot M, Anderson R, Freedland KE, Clouse RE, Lustman PJ. Association of depression to diabetes complications: a metaanalysis. Psychosomatic Med. 2001;63(4): 619-30.
36. Gross R, Olfson M, Gameroff MJ, Carasquillo $\mathrm{O}$, Shea S, Feder A, et al. Depression and glycemic control in Hispanic primary care patients with diabetes. J Gen Int Med. 2005;20(5): 460-6.

37. Kilbourne AM, Reynolds III CF, Good CB, Sereika SM, Justice AC, Fine MJ. How does depression influence diabetes medication adherence in older patients? Am J Ger Psych. 2005;13(3):202-10.

38. Awad N, Gagnon M, Messier C. The relationship between impaired glucose tolerance, type 2 diabetes, and cognitive function. J Clin Exp Neuropsychol. 2004;26(8):1044-80.

39. Hänninen J, Takala J, Keinänen-Kiukaanniemi S. Quality of life in NIDDM patients assessed with the SF-20 questionnaire. Diabetes Res Clin Pract. 1998;42(1):17-27.

40. Redekop WK, Koopmanschap MA, Stolk RP, Rutten GE, Wolffenbuttel BH, Niessen LW. Health-related quality of life and treatment satisfaction in Dutch patients with type 2 diabetes. Diabetes Care. 2002;25(3):458-63.

41. Wexler DJ, Grant RW, Wittenberg E, Bosch JL, Cagliero E, Delahanty L, et al. Correlates of health-related quality of life in type 2 diabetes. Diabetologia. 2006;49(7):1489-97.

42. Gonzélez C, Stern MP, Mitchell BD, Valdez RA, Haffner SM, Pérez BA. Clinical characteristics of type II diabetic subjects consuming high versus low carbohydrate diets in Mexico City and San Antonio, Texas. Diabetes Care. 1994;17(5):397-404.

43. Aguilar-Salinas CA, Monroy OV, GomezPerez FJ, Chavez AG, Esqueda AL, Cuevas VM, et al. Characteristics of patients with type 2 diabetes in Mexico: results from a large population-based nationwide survey. Diabetes Care. 2003;26(7):2021-6.

44. Keinänen-Kiukaanniemi $\mathrm{S}$, Ohinmaa $\mathrm{A}, \mathrm{Pa}$ junpaa $\mathrm{H}$, Koivukangas $\mathrm{P}$. Health related quality of life in diabetic patients as measured by the Nottingham Health Profile. Diab Med. 1996;13(4):382-8.

45. Hörnquist JO, Wikby A, Stenström U, Andersson PO, Akerlind I. Type II diabetes and quality of life: a review of the literature. Pharmacoeconomics. 1995;8(suppl 1):12-6.

46. Cox DJ, Gonder-Frederick L. Major developments in behavioral diabetes research. J Consult Clin Psychol. 1992;60(4):628-38.

47. Wilson W, Ary DV, Biglan A, Glasgow RE, Toobert DJ, Campbell DR. Psychosocial predictors of self-care behaviors (compliance) and glycemic control in non-insulin-dependent diabetes mellitus. Diabetes Care. 1986;9(6):614-22.

48. Marin G, Marin BV. Research with Hispanic populations. Newbury Park (CA): Sage; 1991.

Manuscript received 15 May 2007. Revised version accepted for publication 14 January 2008. 
RESUMEN Objetivos. Analizar los dominios de salud física y mental de la calidad de vida relacionada con la salud (CVRS) en una población binacional de adultos con diabetes

\section{La calidad de vida relacionada con la salud en una población diabética binacional de la frontera Texas-México} tipo 2 en la frontera Texas-México y explorar los factores individuales y sociales relacionados con el estado de la salud física y mental.

Métodos. Se realizó un muestreo de conveniencia de personas de 18 años de edad o más con diabetes tipo 2 que vivían en Lower Rio Grande Valley, al sur de Texas, y en Reynosa, Tamaulipas, México, y se les realizó una entrevista estructurada presencial. La CVRS se midió mediante los componentes abreviados de salud física y mental del MOS-SF8 (Medical Outcomes Study Short Form 8). Entre los factores relacionados con la CVRS estaban las características demográficas, los factores de salud, el acceso a la atención sanitaria y el apoyo familiar. Se compararon las características de las muestras mediante la prueba de la $t$ de Student o la prueba de la U de Mann-Whitney. Las asociaciones entre las variables independientes y la dependiente se analizaron mediante modelos de regresión logística múltiple, ajustados y sin ajustar.

Resultados. No se encontraron diferencias significativas entre los entrevistados de Valley y de Reynosa en cuanto a la puntuación del estado de salud física y mental. Los participantes de Valley con menor estatus socioeconómico y los que consideraban que los parientes que los apoyaban tenían un "bajo" nivel de conocimiento sobre la diabetes presentaron una mayor probabilidad de informar un peor estado de salud física que los que no tenían esas características. En el grupo de Reynosa, el peor estado de salud física se asoció con la duración de la diabetes y el uso de insulina. En ambos grupos, las personas con síntomas clínicos de depresión tuvieron una mayor probabilidad de informar una peor salud física y mental que los que no presentaban esos síntomas.

Conclusiones. La CVRS es un importante criterio en el análisis del estado de salud. La comprensión de los niveles de CVRS de los diabéticos que viven en la frontera entre los EE.UU. y México y de los factores que influyen en su CVRS puede contribuir a mejorar los programas de control de la diabetes.

Palabras clave Calidad de vida, diabetes mellitus tipo 2, factores de riesgo, salud fronteriza, americanos mexicanos, Texas, México, Estados Unidos. 